\title{
Structure Sensitivity of Reactions between Cyclopropane and Hydrogen on Supported Ruthenium Catalysts
}

\section{INTRODUCTION}

The hydrogenation of cyclopropane on $\mathrm{Pt}$ is often cited as a classic example of structure-insensitive reactions. The objective of this work is to explore whether the structure insensitivity of this reaction can be generalized for other metals such as $\mathrm{Ru}$. Cyclopropane and hydrogen can in principle undergo the following three reactions:

$$
\begin{aligned}
c-\mathrm{C}_{3} \mathrm{H}_{6}+\mathrm{H}_{2} & \rightarrow \mathrm{C}_{3} \mathrm{H}_{8} \\
c-\mathrm{C}_{3} \mathrm{H}_{6}+2 \mathrm{H}_{2} & \rightarrow \mathrm{CH}_{4}+\mathrm{C}_{2} \mathrm{H}_{6} \\
c-\mathrm{C}_{3} \mathrm{H}_{6}+\mathrm{H}_{2} & \rightarrow 3 \mathrm{CH}_{4}
\end{aligned}
$$

Reaction (1) is called "hydrogenation," reaction (2) "selective hydrocracking," and reaction (3) "nonselective hydrocracking." On Pd, Ir, and Pt only reaction (1) is observed, while $\mathrm{Co}_{0}, \mathrm{Rh}$, and $\mathrm{Os}$ are active for reactions (1) and (2), and $\mathrm{Fe}, \mathrm{Ni}$, and $\mathrm{Ru}$ are able to catalyze all three reactions (1-5).

The structure sensitivity of the three cyclopropane reactions on $\mathrm{Ru}$ catalysts has not yet been investigated in great detail. In previous work it was discovered that the nonselective hydrocracking reaction occurred only on catalysts containing relatively large $\mathrm{Ru}$ particles (I). On highly dispersed $\mathrm{Ru}$ catalysts, the nonselective hydrocracking reaction did not take place at all, and instead an increase in activity for reactions (1) and (2) with increasing $\mathrm{Ru}$ dispersion was noted (4). These findings indicated an apparent structure sensitivity of all three reactions of cyclopropane, and prompted us to investigate this phenomenon more closely. In the present study, the dispersion of $\mathrm{Ru}$ and the nature of the support are varied systematically in order to evaluate their relative contributions to the activity and selectivity in the three cyclopropane reactions.

\section{EXPERIMENTAL}

Ruthenium catalysts supported on $\mathrm{SiO}_{2}$, $\mathrm{Al}_{2} \mathrm{O}_{3}, \mathrm{SiO}_{2}-\mathrm{Al}_{2} \mathrm{O}_{3}, \mathrm{MgO}$, and $\mathrm{NaY}$ zeolite were prepared according to the following methods to obtain a wide range of Ru metal dispersions:

$\operatorname{Method}(a)$ : Impregnation of the support by the incipient wetness method with a solution of $\mathrm{RuCl}_{3} \cdot \mathrm{H}_{2} \mathrm{O}$ (Rudi-Pont reagent grade), followed by drying at $383 \mathrm{~K}$ for $4 \mathrm{hr}$ and reduction in flowing $\mathrm{H}_{2}$ at $673 \mathrm{~K}$ for 2 hr.

Method (b): Suaking of the support in an excess volume of aqueous solution of $\mathrm{RuCl}_{3} \cdot \mathrm{H}_{2} \mathrm{O}$ (Rudi-Pont reagent grade), filtering, drying at $383 \mathrm{~K}$ for $4 \mathrm{hr}$, reduction in flowing $\mathrm{H}_{2}$ at $673 \mathrm{~K}$ for $2 \mathrm{hr}$.

Method (c): Soaking of the support in an excess volume of aqueous solution of $\mathrm{RuCl}_{3} \cdot \mathrm{H}_{2} \mathrm{O}$ (Rudi-Pont reagent grade), filtering, drying at $388 \mathrm{~K}$ for $4 \mathrm{hr}$, reduction in $0.5 \mathrm{M} \mathrm{NaOH}$ solution of hydrazine, followed by $4 \mathrm{hr}$ evacuation at $388 \mathrm{~K}$ and subsequent reduction in flowing $\mathrm{H}_{2}$ at $673 \mathrm{~K}$ for $2 \mathrm{hr}$.

Method $(d)$ : Heating of the support under reflux with a solution of $\mathrm{Ru}_{3}(\mathrm{CO})_{12}$ in toluene, drying under vacuum at $383 \mathrm{~K}$, followed by reduction in flowing $\mathrm{H}_{2}$ at $673 \mathrm{~K}$ for $2 \mathrm{hr}$.

Method (e): Ion exchanging $\mathrm{Ru}$ into $\mathrm{NaY}$ zeolite using an aqueous solution of $\mathrm{Ru}\left(\mathrm{NH}_{3}\right)_{6} \mathrm{Cl}_{3}$, followed by heating under dynamic vacuum to $673 \mathrm{~K}$ with a heating rate of $1 \mathrm{~K} / \mathrm{min}$, and reduction in flowing hydrogen at $723 \mathrm{~K}$ for $2 \mathrm{hr}$.

The details of catalyst preparation and 
TABLE 1

Summary of Catalyst Characterization, Apparent Activation Energies, $E_{i}$, and Preexponential Factors, $A_{i}$, for Reactions (1) and (2)

\begin{tabular}{|c|c|c|c|c|c|c|c|}
\hline \multirow[t]{2}{*}{ Catalyst } & \multirow{2}{*}{$\begin{array}{c}\% \mathrm{Ru} \\
\text { dispersion }\end{array}$} & \multirow{2}{*}{$\begin{array}{l}\text { Preparation } \\
\text { method }\end{array}$} & \multicolumn{5}{|c|}{ Arrhenius parameters based on linear portion of Arrhenius plots } \\
\hline & & & $\begin{array}{c}\text { Temperature } \\
\text { range }(\mathbf{K})\end{array}$ & $\begin{array}{c}E_{1} \\
(\mathrm{k} J / \mathrm{mol})\end{array}$ & $\ln A_{1}$ & $\begin{array}{c}E_{2} \\
(\mathrm{~kJ} / \mathrm{mol})\end{array}$ & $\ln A_{2}$ \\
\hline $4.44 \% \mathrm{Ru} / \mathrm{MgO}$ & 7.1 & $b$ & $302-374$ & $33.5 \pm 12$ & $7.5 \pm 3$ & $44.0 \pm 12$ & $6.4 \pm 3$ \\
\hline $2.10 \% \mathrm{Ru} / \mathrm{MgO}$ & 13.5 & b & $312-372$ & $24.3 \pm 1.7$ & $4.1 \pm 0.6$ & $38.9 \pm 3.8$ & $7.3 \pm 1.3$ \\
\hline $3.86 \% \mathrm{Ru} / \mathrm{SiO}_{2}$ & 26.0 & $\mathbf{a}$ & $324-373$ & $35.6 \pm 7.5$ & $9.9 \pm 2.5$ & $46.9 \pm 6.7$ & $12.2 \pm 1.7$ \\
\hline $3.07 \mathrm{Ru} / \mathrm{MgO}$ & 31.7 & c & $314-375$ & $24.3 \pm 4.6$ & $7.4 \pm 1.5$ & $39.3 \pm 5.8$ & $10.7 \pm 2.0$ \\
\hline $3.10 \% \mathrm{Ru} / \mathrm{SiO}_{2}-\mathrm{Al}_{2} \mathrm{O}_{3}$ & 33.0 & $\mathbf{a}$ & $309-354$ & $32.2 \pm 7.9$ & $11.4 \pm 2.8$ & $40.2 \pm 7.5$ & $12.7 \pm 2.8$ \\
\hline $2.10 \% \mathrm{Ru} / \mathrm{SiO}_{2}$ & 36.5 & $\mathbf{a}$ & $325-363$ & $48.9 \pm 9.6$ & $17.8 \pm 3.3$ & $50.6 \pm 8.4$ & $16.8 \pm 2.9$ \\
\hline $3.00 \% \mathrm{Ru} / \mathrm{SiO}_{2}$ & 43.0 & $\mathbf{a}$ & $323-373$ & $35.1 \pm 7.1$ & $13.2 \pm 2.6$ & $51.0 \pm 9.2$ & $12.2 \pm 2.1$ \\
\hline $5.38 \% \mathrm{Ru} / \mathrm{MgO}$ & 60.0 & d & $317-371$ & $26.8 \pm 2.5$ & $7.3 \pm 0.9$ & $45.1 \pm 7.1$ & $12.5 \pm 2.5$ \\
\hline $0.19 \% \mathrm{RuNaY}$ & 94.5 & e & $290-323$ & $42.7 \pm 5.9$ & $15.3 \pm 2.2$ & $48.1 \pm 5.9$ & $15.5 \pm 2.3$ \\
\hline
\end{tabular}

characterization were described previously (4, 6-14). Table 1 lists the catalysts and summarizes the pertinent characterization data. The reactions between cyclopropane and hydrogen were studied at atmospheric pressure in a Pyrex glass flow reactor containing about $100 \mathrm{mg}$ of catalyst powder. Differential reaction conditions with conversions less than $5 \%$ were maintained. A glass-shielded thermocouple was placed inside the reactor immediately above the catalyst powder. The feed composition was $3 \%$ cyclopropane, $20 \% \mathrm{H}_{2}$, and $77 \% \mathrm{He}$. Prior to admission into the reactor, prepurified hydrogen was passed through a commercial hydrogen purifier cell containing a Pd membrane. Ultrahigh-purity helium was passed through an oxygen removing purifier. High-purity cyclopropane was used without further treatment. The analysis of the reactants and products was carried out by gas chromatography with a silica gel column operated at $80^{\circ} \mathrm{C}$.

Before exposing the catalysts to the reactant mixture, the reactor was flushed with He gas at room temperature. Catalyst pretreatment was performed in flowing $\mathrm{H}_{2}$ at $673 \mathrm{~K}$. At each reaction temperature investigated, the first sample of the reactor effluent was taken after $120 \mathrm{~s}$ on stream, and the activity obtained at this time was arbitrarily chosen as "initial activity." Additional samples were collected at time intervals of about $7-10 \mathrm{~min}$ over extended periods of time to monitor the deactivation behavior. After each run, the catalysts were regenerated in flowing $\mathrm{H}_{2}$ at $673 \mathrm{~K}$. Based on test runs with different reactant flow rates and different amounts of inert diluent in the catalyst bed, heat and mass transfer limitations could be excluded (15). In blank runs no reaction was found to occur on the reactor walls or on the catalyst supports under the experimental conditions.

\section{RESULTS AND DISCUSSION}

Reactions (1) and (2) were found to occur on all $\mathrm{Ru}$ catalysts. The occurrence of reaction (3), however, was observed only on the first four catalysts listed in Table 1. The reaction rates were determined by the following equation:

$$
N_{i}=F x_{i} / W_{\mathrm{s}} .
$$

$N_{i}$ represents the turnover frequency per $\mathrm{Ru}$ surface atom, $F$ the feed rate of cyclopropane (moles/s), and $W_{\mathrm{s}}$ the number of moles of $\mathrm{Ru}$ on the catalyst surface as determined by hydrogen chemisorption, assuming a stoichiometry of $\mathrm{H} / \mathrm{Ru}_{\mathrm{s}}=1 . x_{i}$ is the fractional conversion of cyclopropane according to reaction $i(i=1,2,3)$. $x_{i}$ is calculated from the product distribution in the reactor effluent.

Figure 1 shows the Arrhenius plots obtained for reaction (1). All the data points shown on the Arrhenius plots were col- 


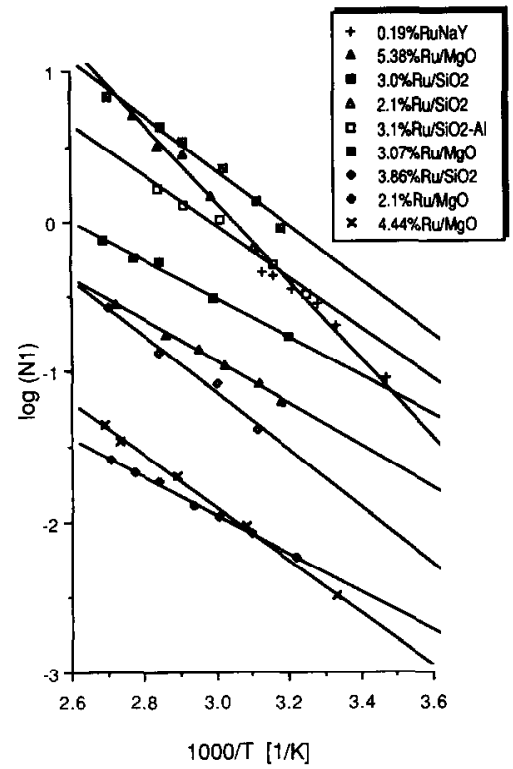

FIG. 1. Arrhenius plots for reaction (1) over Ru catalysts. The turnover frequencies are normalized with respect to $\mathrm{Ru}$ surface atoms as determined by $\mathrm{H}_{2}$ chemisorption.

lected under differential reaction conditions. Additional data points collected at higher temperatures and conversions started to deviate from linearity and are not included in Fig. 1. Most of the Arrhenius plots showed a slight downward curvature at $1000 / T$ values smaller than 2.6 , as illustrated in Fig. 2 for the $3.86 \% \mathrm{Ru} / \mathrm{SiO}_{2}$ catalyst. Nonlinear Arrhenius plots are usually indicators for changes in the relative surface coverage of reactants, changes in the rate-determining step, or changes in the relative contribution of different reaction pathways in parallel reactions (16). In addition, artifacts such as more rapid deactivation at elevated temperatures or the onset of transport limitations could contribute to the nonlinearity.

The activity trends for selective hydrocracking according to reaction (2) were similar to those for reaction (1), and the Arrhenius plots for these two reactions tended to parallel each other, as illustrated for $3.86 \% \mathrm{Ru} / \mathrm{SiO}_{2}$ in Fig. 2. Table 1 summarizes the apparent activation energies and preexponential factors determined from the linear portions of the Arrhenius plots for reactions (1) and (2). On all catalysts, the apparent activation energy of rcaction (2) was slightly higher than that of reaction (1).

Closer inspection of Fig. 1 and Table 1 reveals a qualitative trend of increasing activity by several orders of magnitude with increasing $\mathrm{Ru}$ metal dispersion, in striking contrast to the behavior of $\mathrm{Pt}$ where the activity remains constant over a wide range of metal dispersions $(2,17-21)$. Only the two Ru catalysts with the highest nominal metal dispersion $(0.19 \%$ RuNaY and $5.38 \% \mathrm{Ru} / \mathrm{MgO}$ ) deviated from this qualitative activity trend. It should be noted that these two highly dispersed catalysts differ from the rest of the samples insofar as the $5.38 \% \mathrm{Ru} / \mathrm{MgO}$ catalyst was prepared from Ru carbonyl, while the catalysts with nominal dispersion of $94.5 \%$ were prepared via ion exchange into $\mathrm{NaY}$ zeolite. All the other catalysts were prepared via conventional impregnation techniques.

Since the activity comparisons were made based on initial activities after $120 \mathrm{~s}$

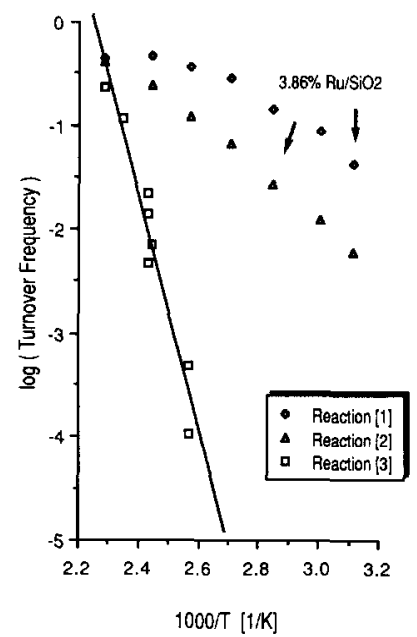

FIG. 2. Arrhenius plot for reaction (3) over catalysts $4.44 \% \mathrm{Ru} / \mathrm{MgO}, 2.1 \% \mathrm{Ru} / \mathrm{MgO}, 3.86 \% \mathrm{Ru} / \mathrm{SiO}_{2}$, and $3.07 \% \mathrm{Ru} / \mathrm{MgO}$. On the other $\mathrm{Ru}$ catalysts listed in Table 1 no activity for reaction (3) could be detected under the reaction conditions. For comparison, data for reactions (1) and (2) on $3.86 \% \mathrm{Ru} / \mathrm{SiO}_{2}$ are included. 
on stream, it was important to check the deactivation rates to rule out that the activity trends shown in Fig. 1 could be due to different degrees of deactivation after the first $120 \mathrm{~s}$. The relative extent of deactivation, $\beta$, was determined by dividing the total activity at any time $t$ by the total "initial" activity after $120 \mathrm{~s}$ on stream:

$$
\beta=N_{t} / N_{t=120 \mathrm{~s}} .
$$

All catalysts deactivated with time on stream. The relative deactivation $\beta$ appeared to be not strongly dependent on temperature within the temperature regime shown in the Arrhenius plots (Fig. 1). However, the nature of the support and the metal dispersion seemed to exert some influence on the rate and extent of deactivation. For the Ru catalysts supported on $\mathrm{MgO}, \beta$ reached an asymptotic limit of 0.4-0.6 after $30 \mathrm{~min}$ on stream. The $3.86 \%$ $\mathrm{Ru} / \mathrm{SiO}_{2}$ catalyst showed similar deactivation behavior, while the more highly dispersed $\mathrm{Ru} / \mathrm{SiO}_{2}$ catalysts, $\mathrm{Ru} / \mathrm{SiO}_{2}-$ $\mathrm{Al}_{2} \mathrm{O}_{3}$ and $\mathrm{RuNaY}$, deactivated more severely, reaching $\beta$ values of about 0.1 after $30 \mathrm{~min}$ on stream. Since the deactivation was most pronounced on the most active catalysts, the qualitative trend of increasing activity with increasing dispersion cannot be attributed to artifacts caused by differences in deactivation rates. It is, however, conceivable that the two catalysts with the highest metal dispersion lost activity so rapidly that the "initial" activity after $120 \mathrm{~s}$ on stream was lower than one would expect based on the trends shown in Fig. 1.

Reaction (3) reached measurable rates only at temperatures higher than about $\mathbf{3 9 0}$ $\mathrm{K}$ (Fig. 2) and was only observed on the first four catalysts listed in Table $1(4.44 \%$ $\mathrm{Ru} / \mathrm{MgO}, 2.10 \% \mathrm{Ru} / \mathrm{MgO}, 3.86 \% \mathrm{Ru} / \mathrm{SiO}_{2}$, and $3.07 \% \mathrm{Ru} / \mathrm{MgO}$ ). Within experimental error, the data points of the Arrhenius plots of these four catalysts fell onto a single straight line, giving an apparent activation energy, $E_{3}=94 \pm 16 \mathrm{~kJ} / \mathrm{mol}$ and $\ln A_{3}=58$ \pm 10 . To bring the activity for reaction (3) into perspective with reactions (1) and (2), data for reactions (1) and (2) on one of the catalysts $\left(3.86 \% \mathrm{Ru} / \mathrm{SiO}_{2}\right)$ are included in Fig. 2. On all the other catalysts listed in Table 1, reaction (3) was not detected in the temperature regime shown in Fig. 2.

Previous work has clearly shown that reaction (3) represents a true parallel reaction, and not a consecutive reaction of propane or ethane $(1,3,4)$. To find out why only the first four catalysts from Table 1 were active for reaction (3), the various $\mathrm{Ru}$ catalysts were examined by transmission electron microscopy. The four catalysts with demonstrated activity for reaction (3) had the lowest nominal $\mathrm{Ru}$ metal dispersion. However, one of these catalysts had a dispersion of $31.7 \%$, while another sample with roughly the same dispersion (33\%) proved to be completely inactive for reaction (3). To check whether a critical value of $\mathrm{Ru}$ particle size was required to generate activity for reaction (3), the Ru particle size distributions derived from transmission electron microscopy $(10,13,14,22)$ were compared for catalysts falling on either side of the threshold for reaction (3). It was found that all the catalysts having activity for reaction (3) contained a significant number of metal particles larger than 5-6 nm, while the catalysts with no activity for reaction (3) showed a total lack of metal particles larger than 4-5 $\mathrm{nm}$. Therefore, the presence of $\mathrm{Ru}$ particles with diameters of approximately $5 \mathrm{~nm}$ or larger seems to be important for allowing reaction (3) to proceed at measurable rates. Further proof was provided by sintering experiments demonstrating that highly dispersed Ru catalysts unable to catalyze reaction (3) can be made active for this reaction by sintering at temperatures of about $1000 \mathrm{~K}$ in air for $4 \mathrm{hr}$ (I) resulting in the formation of Ru particles larger than $5 \mathrm{~nm}$.

On very small metal particles, it appears to be difficult to form multiple bonds between metal atoms and hydrocarbon molecules $(23,24)$, thereby impeding a probable precursor step for the successful rupture of 
all three $\mathrm{C}-\mathrm{C}$ bonds in cyclopropane required for reaction (3).

The selectivity, $S_{1}$, for propane formation via reaction (1) was determined by the following expression:

$$
S_{1}=N_{1} /\left(N_{1}+N_{2}+N_{3}\right) \text {. }
$$

The first four catalysts in Table 1 which were active for reaction (3) showed a gradual decline in $S_{1}$ from a value of 0.9 at $300 \mathrm{~K}$ to 0.8 at $380 \mathrm{~K}$, followed by a steep decline of $S_{1}$ to a value of 0.4 at $440 \mathrm{~K}$. The gradual decline of $S_{1}$ with temperature is expected even in absence of reaction (3), since the activation energies for reaction (2) tend to be slightly higher than those of reaction (1) (Table 1). In addition, differences in Arrhenius plot curvatures at higher temperatures can contribute to declines in $S_{1}$ at higher temperatures. Therefore, the $\mathrm{CH}_{4} / \mathrm{C}_{2} \mathrm{H}_{6}$ ratio was introduced as an additional parameter to test for the presence of reaction (3): As long as only reactions (1) and (2) are operable, the $\mathrm{CH}_{4} / \mathrm{C}_{2} \mathrm{H}_{6}$ ratio should stay close to unity, while the ratio of $\mathrm{CH}_{4} / \mathrm{C}_{2} \mathrm{H}_{6}$ has to exceed unity as soon as reaction (3) starts to contribute. The first four catalysts in Table 1 were active for reaction (3), as confirmed by a sudden rise in the $\mathrm{CH}_{4} / \mathrm{C}_{2} \mathrm{H}_{6}$ ratio at temperatures above $390 \mathrm{~K}$.

The selectivities, $S_{1}$, of the other catalysts which were inactive for reaction (3) remained more or less constant at a value of 0.9 to 0.8 as the temperature increased from 300 to $440 \mathrm{~K}$, except for catalyst $5.38 \%$ $\mathrm{Ru} / \mathrm{MgO}$ which exhibited a significant drop in selectivity as the temperature increased beyond $360 \mathrm{~K}$, reaching a final value of $S_{1}=$ 0.4 at $440 \mathrm{~K}$. However, the $\mathrm{CH}_{4} / \mathrm{C}_{2} \mathrm{H}_{6}$ ratio on all these catalysts including $5.38 \%$ $\mathrm{Ru} / \mathrm{MgO}$ remained constant at values of slightly less than unity. Therefore, it can be concluded that the decrease in selectivity of catalyst $5.38 \% \mathrm{Ru} / \mathrm{MgO}$ was not due to the onset of reaction (3), but caused by a more pronounced contribution of reaction (2) as the temperature increased.

The selectivity, $S_{1}$, and the $\mathrm{CH}_{4} / \mathrm{C}_{2} \mathrm{H}_{6}$ ratio remained constant with time on stream and were not affected by catalyst deactivation, suggesting uniform deactivation of active sites for cyclopropane hydrogenation and selective hydrocracking. The deactivation appeared to be largely due to carbonaceous deposits, since methane was evolved during regeneration of deactivated catalysts in $\mathrm{H}_{2}$ at $673 \mathrm{~K}$, and the "initial" activity of the catalysts could be fully restored.

In absence of reaction (3), the $\mathrm{CH}_{4} / \mathrm{C}_{2} \mathrm{H}_{6}$ ratio tended to be slightly less than unity. $\mathrm{A}$ possible explanation for this phenomenon could be that the $C_{1}$ intermediate represents the main precursor for carbonaceous deposits on the catalyst surface, thereby decreasing the relative amount of methane in the reactor effluent. The methane deficiency of the product stream could also be due to dimerization of $C_{1}$ species to $C_{2}$ species, as suggested by Merta and Ponec (25).

For Ru catalysts prepared by conventional impregnation techniques, a qualitative trend of increasing activity with increasing Ru metal dispersion was observed. This trend probably reflects an increase in the concentration of small Ru particles with diameters of less than $4-5 \mathrm{~nm}$, which seem to possess surface sites that are very effective in catalyzing the ring opening via hydrogenation or selective hydrocracking. Judging from the results of transmission electron microscopy, Ru metal particles larger than about $5 \mathrm{~nm}$ appear to be required for nonselective hydrocracking to occur. On such larger metal particles it is more likely to find Ru atom ensembles with high coordination number and low index planes exposed on the surface.

\section{ACKNOWLEDGMENTS}

Support for this work by the National Science Foundation is gratefully acknowledged. The authors express their gratitude to Dr. S. Galvagno, Dr. G. R. Tauszik, Dr. F. Garbassi, and their co-workers for their contribution to catalyst preparation and partial characterization. We also thank Dr. A. K. Datye and Dr. A. G. Shastri, and Mr. A. Sachdev for their contribution to catalyst characterization and helpful discussions. 


\section{REFERENCES}

1. Galvagno, S., Schwank, J., and Parravano, G., J. Catal. 61, 223 (1980).

2. Dalla Betta, R. A., Cusumano, J. A., and Sinfelt, J. H., J. Catal. 19, 343 (1970).

3. Wallace, H. F., and Hayes, K. E., J. Catal. 29, 83 (1973).

4. Sajkowski, D. J., Lee, J. Y., Schwank, J., Tien, Y. H., and Goodwin, J. G., Jr., J. Catal. 97, 549 (1986).

5. Somorjai, G., "Chemistry in Two Dimensions, Surfaces,' Cornell Univ. Press, Ithaca, NY, 1981.

6. Bossi, A., Garbassi, F., Orlandi, A., Petrini, G., and Zanderighi, L., in "Preparation of Catalysts II," p. 405. Elsevier, Amsterdam, 1979.

7. Schwank, J., Parravano, G., and Gruber, H. L., J. Catal. 61, 19 (1980).

8. Galvagno, S., Schwank, J., Parravano, G., Garbassi, F., Marzi, A., and Tauszik, G. R., J. Catal. 69, 283 (1981).

9. Galvagno, S., Schwank, J., Gubitosa, G., and Tauszik, G. R., J. Chem. Soc., Faraday Trans. I 78, 2509 (1982).

10. Datye, A. K., PhD thesis, The University of Michigan, Ann Arbor, MI, 1984.

11. Shastri, A. G., and Schwank, J., J. Catal. 95, 271 (1986).

12. Shastri, A. G., and Schwank, J., J. Catal. 95, 284 (1986).

13. Shastri, A. G., and Schwank, J., J. Catal. 98, 191 (1986).

14. Shastri, A. G., Schwank, J., and Galvagno, S., J. Catal. 100, 446 (1986).

15. Koros, R. M., and Nowak, E. J., Chem. Eng. Sci. 22, 470 (1967).

16. Schmid, R., and Sapunov, V. N., "Non-formal Kinetics," Verlag Chemie, Weinheim, 1982.

17. Naccache, C., Kaufherr, N., Defaux, M., Bandiera, J., and Imelik, B., Amer. Chem. Soc. Symp. Ser. 40, 538 (1977).

18. Otero-Shipper, P. H., Wachter, W. A., Butt, J.
B., Burwell, R. L., Jr., and Cohen, J. B., J. Catal. 50, 494 (1977).

19. Wong, S. S., Otero-Shipper, P. H., Wachter, W. A., Inone, Y., Kobayashi, M., Butt, J. B., Burwell, R. L., Jr., and Cohen, J. B., J. Catal. 64, 84 (1980).

20. Kahn, D. R., Petersen, E. E., and Somorjai, G. A., J. Catal. 34, 271 (1974).

21. Boudart, M., Aldag, A., Benson, J. E., Dougharty, M. A., and Harkins, C. G., J. Catal. 6, 92 (1966).

22. Datye, A. K., and Schwank, J., "Proceedings, 8th International Congress on Catalysis," Vol. IV, p. 587. Dechema, Frankfurt-am-Main, 1984.

23. van Broekhoven, E. H., Schoonhoven, J. W. F., and Ponec, V., Surf. Sci. 156, 899 (1985).

24. Schepers, F. J., van Broekhoven, E. H., and Ponec, V., J. Catal. 96, 82 (1985).

25. Merta, R., and Ponec, V., J. Catal. 17, 79 (1969).

\section{J. SchWANK ${ }^{1}$ \\ J. Y. LEE ${ }^{2}$}

Department of Chemical Engineering

The University of Michigan

Ann Arbor, Michigan 48109-2136

\section{J. G. GoodwIN, JR.}

Department of Chemical and Petroleum Engineering

University of Pittsburgh

Pittsburgh, Pennsylvania 15261

Received January 22, 1987

\footnotetext{
${ }^{1}$ To whom correspondence should be addressed.

${ }^{2}$ Present address: Department of Chemical Engineering, University of Texas at Austin, Austin, TX.
} 